\title{
Is 8860 variation a rare polymorphism or associated as a secondary effect in HCM disease?
}

Massoud Houshmand ${ }^{1}$, Maryam Montazeri ${ }^{1}$, Nafiseh Kuchekian², Freidoon Noohi ${ }^{3}$ Givtaj Nozar ${ }^{3}$, Akram Zamani 1National Institute for Genetic Engineering and Biotechnology, Tehran, Iran
2Special Medical Center, Tehran, Iran
3Iran University of Medical Sciences, Shaheed Rajaei Cardiovascular Medical Center,
Tehran, Iran

Submitted: 26 April 2010

Accepted: 30 September 2010

Arch Med Sci 2011; 7, 2: 242-246

DOI: 10.5114 /aoms.2011.22074

Copyright (c) 2011 Termedia \& Banach

\section{Abstract}

Introduction: mtDNA defects, both deletions and point mutations, have been associated with hypertrophic cardiomyopathies. The aim of this study was to establish a spectrum for mtDNA mutations in Iranian hypertrophic cardiomyopathy (HCM) patients.

Material and methods: The control group was chosen among the special medical centre visitors who did not have hypertrophic cardiomyopathy or any related heart disease. Hypertrophic cardiomyopathy (HCM) is widely accepted as a pluricausal or multifactorial disease. Because of the linkage between energy metabolism in the mitochondria and cardiac muscle contraction, it is reasonable to assume that mitochondrial abnormalities may be responsible for some forms of HCM. Point mutations and deletions in the two hot spot regions of mtDNA were investigated by PCR and sequencing methods.

Results: Some unreported point mutations have been found in this study but no deletion was detected. Meanwhile some of these point mutations have been investigated among HCM patients for the first time.

Conclusions: A8860G transition was detected in a high proportion, raising the question whether this rare polymorphism is associated as a secondary effect in HCM disease.

Key words: hypertrophic cardiomyopathy, mtDNA mutation disease.

\section{Introduction}

The cardiomyopathies are a clinically and genetically heterogeneous group of cardiac diseases in which the myocardium is primarily involved. Three distinct categories of cardiomyopathy can be classified by functional and pathological criteria: hypertrophic cardiomyopathy (HCM), dilated cardiomyopathy (DCM) and restrictive cardiomyopathy. It has been proposed that approximately $45-50 \%$ of familial hypertrophic cardiomyopathy cases are due to mutations in genes encoding contractile proteins of the sarcomere including the á-cardiac myosin heavy chain gene, the cardiac troponin T gene and the á-tropomyosin gene.

It is now known that hypertrophic cardiomyopathy can occur as a result of point mutations in the highly conserved transfer RNA genes of mitochondrial DNA. The mitochondrial genome, exclusively inherited through the maternal line, is a 16.5 kilobase $(\mathrm{kb})$, circular, double stranded

\section{Corresponding author:}

Massoud Houshmand MD, PhD

National Institute for Genetic

Engineering

and Biotechnology

Tehran, Iran

Phone: +98 2144580390

Fax: +98 2144580399

E-mail: massoudh@nigeb.ac.ir 
molecule that encodes two ribosomal RNAs, 22 transfer RNAs and 13 proteins involved in the mitochondrial respiratory chain and oxidative phosphorylation system. The oxidative phosphorylation system is fundamental to the synthesis of cellular ATP and consequently pathogenic mutations of mitochondrial DNA are believed to cause disease by impairing the function of the mitochondrial respiratory chain and oxidative phosphorylation system, thereby decreasing cellular ATP synthesis.

Mitochondrial DNA point mutations have been identified in a broad spectrum of clinical phenotypes. The majority of these are associated with neurological disorders such as the mitochondrial myopathies and encephalomyopathies, although a number of mitochondrial DNA point mutations have been reported in patients with hypertrophic cardiomyopathy, either alone or as part of a multisystem disorder [1]. In this study we investigated point mutation diversities in the two hot spot regions of mitochondrial DNA among Iranian HCM patients.

\section{Material and methods}

\section{Patients}

A total of 31 hypertrophic cardiomyopathic adult patients of unrelated families were selected based on their medical examination, electrocardiogram, Holter monitoring, and angiography [2]. All of the patients were informed regarding the aims of the study and gave their consent for genetic analysis. The control group consisted of 100 visitors of the special medical centre who were chosen among the visitors without hypertrophic cardiomyopathic disease or any related heart disease and with no family history of this disease.

\section{DNA extraction}

Genomic DNA was extracted from $5 \mathrm{ml}$ of peripheral blood using a DNA extraction kit (Diatom DNA Extraction Kit, Genefanavaran, Tehran, Iran).

\section{mtDNA deletion analysis}

We screened the $31 \mathrm{HCM}$ patients for mtDNA deletions according to previous work carried out by Houshmand et al. The PCRs were performed in 35 cycles composed of the following steps: $94^{\circ} \mathrm{C}$ for $1 \mathrm{~min}, 55^{\circ} \mathrm{C}$ for $1 \mathrm{~min}$ and $72^{\circ} \mathrm{C}$ for $35 \mathrm{~s}$. The deletionprone region between $\mathrm{nt} 5461$ of the light strand and nt 15000 of the heavy strand was investigated in all patients using the primers ONP 86, ONP 89, ONP10, ONP 74, ONP 25 and ONP 99 (Table I). The distances between the primers were long enough to allow amplification only if a part of the DNA between the respective primers was deleted. The primer pair ONP 86/ONP 89 was used to amplify a normal internal mtDNA fragment in a region which is seldom afflicted by deletions, thus serving as a control in the PCR analysis. We categorized mtDNA deletions into 4 classes of A, B, C, and D corresponding to 8.7-, 7.5-, 5- and 7.5-kb deletions, respectively (Table II) [3].

\section{PCR sequencing}

The first mtDNA region from nt 1441 to nt 6001 including RNR2, TL1, ND1, TQ, ND2 and the second region (1,635 bp) from nt 7377 to nt 9031 that includes CO2 and ATP6 were amplified according to the method by Ahari et al. [4].

Table I. Primers used for mtDNA deletion analysis

\begin{tabular}{|lc|}
\hline ONP 86 (LF): 5461-5480 (ND2) & 5'-CCC TTA CCA CGC TAC TCC TA-3' \\
\hline ONP 89 (HB): 5740-5721 (OL) & 5'-GGC GGG AGA AGT TTG AA-3' \\
\hline ONP 10 (HB): 15000-14981 (Cytb) & 5'-TTG GCG TGA AGG TAG CGG AT-3' \\
\hline ONP 74 (HB): 13640-13621 (ND50) & 5'-GGT TGA CCT GTT AGG GTG AG-3' \\
\hline ONP 25 (LF): 8161-8180 (COII) & 5'-CTA CGG TCA ATG CTC TGA AA-3' \\
\hline ONP 99 (HB): 16150-16131 (D-loop) & 5'-GTG GTC AAG TAT TTA TGG TA-3' \\
\hline
\end{tabular}

Table II. Primers used for detection of 4 deletions

\begin{tabular}{|lccccc|}
\hline Primers & Starting point & Ending point & Deletion length [Kb] & PCR product length [bp] & Deletion \\
\hline ONP 86, ONP 10 & 5461 & 15000 & 8.7 & 500 & A \\
\hline ONP 86, ONP 74 & 5461 & 13640 & 7.5 & 680 & B \\
\hline ONP 25, ONP 74 & 8180 & 13640 & 5 & 420 & C \\
\hline ONP 25, ONP 99 & 8180 & 16150 & 7.5 & 970 & D Internal control \\
\hline ONP 86, ONP 89 & 5461 & 5740 & - & 279 & \\
\hline
\end{tabular}


Table III. Primers used for mtDNA sequencing

\begin{tabular}{|lll|}
\hline F60 & $1441-1460$ & 5'-AGT AGA GTG CTT AGT TGA GC-3' \\
\hline R63 & $3140-3121$ & 5'-TCT CTT GTC CTT TCG TAC AG-3' \\
\hline F62 & $3001-3020$ & 5'-GGA CAT CCC GAT GGT GCA GC-3' \\
\hline R65 & $4650-4631$ & 5'-GGA AAT ACT TGA TGG CAG CT-3 $^{\prime}$ \\
\hline F64 & $4491-4540$ & 5'-GTC ATC TAC TCT ACC TAC TT-3' \\
\hline R67 & $6020-6001$ & 5'-CTG GAG TGA AAT AAG GAG GCT TA-3' \\
\hline F21 & $7377-7396$ & 5'-CCA AAT AGG TGC ATG AGT AG-3' \\
\hline R56 & $9050-9031$ & \\
\hline
\end{tabular}

PCR products were checked on $1 \%$ agarose gel. MtDNA sequencing was done by using forward and reverse primers (Table III) to detect novel mutations that might impair mitochondrial protein synthesis in the two hot spot regions by a $3700 \mathrm{ABI}$ sequencer (Macrogene Korea). The obtained mtDNA sequences were aligned with a multiple sequence alignment interface CLUSTAL_X and then compared with the reference sequence [5]. MITOMAP: MtDNA Coding Region Sequence Polymorphisms web site was used for investigation and comparison of detected mutations for final conclusions [6].

\section{Results}

In the first step no mtDNA deletion was found among the cases. After that samples from all 31 patients were forwarded for sequencing analysis of the two hot spot regions in mtDNA that included RNR2, TL1, ND1, TQ, ND2, CO2 and ATP6 segments.

Altogether 43 point mutational polymorphisms were found in this study; 10 unpublished polymorphisms were found among them. This finding demonstrates the high variability of human mtDNA. The rest of the polymorphisms have been reported before. No previously reported diseasecausing mutations of mtDNA were found within the sequenced regions of participants (Table IV).

Some of these novel base substitutions do not lead to amino acid exchange and are consequently defined as polymorphisms, such as T1700C. The second group of sequence alterations can be divided into two classes: 1) conservative exchanges, leading to substitution by a homologous amino acid, such as A5480G, and 2) non-homologous substitutions, such as G5466A.

An apparently homoplasmic substitution within tRNA genes was found: T4384C, which affects the T_C loop of tRNA glutamine. No other point mutation was found among the studied mitochondrial tRNA genes.

Except for 3 remarkable mutations (A8860G, A2706G and N3107C) most of these polymorphisms were observed among fewer than 5 patients (Table IV).

\section{Discussion}

During the past decade, more than 100 mutations in 11 causal genes coding for sarcomeric proteins, the $\gamma$ subunit of AMP-activated protein kinase and triplet-repeat syndromes and in mitochondrial DNA, have been identified in patients with hypertrophic cardiomyopathy (HCM). Genotypephenotype correlation studies show significant variability in the phenotype expression of HCM among affected individuals with identical causal mutations. Overall, causal mutations account for a fraction of the variability of phenotypes, and the genetic background, referred to as the modifier genes, plays a significant role. The final phenotype is the result of interactions between the causal genes, the genetic background (modifier genes), and probably environmental factors. The individual modifier genes for HCM remain largely unknown, so a large-scale genome-wide approach and candidate gene analysis are needed [7].

Recently, maternally inherited forms of HCM have been associated with defects in oxidative metabolism that are primarily due to alterations in mtDNA, such as deletions and various point mutations [8-10]. But in fact we did not find any deletion in our study.

Previously, a variety of neurodegenerative and neuromuscular diseases that demonstrate strict maternal inheritance have been attributed to single point mutations in mtDNA. The best characterized examples include MELAS (mitochondrial myopathy, encephalopathy, lactic acidosis, and stroke-like episodes) and MERRF (myoclonic epilepsy and ragged red fibres) [11-15].

Point mutations in tRNA genes have also been attributed to maternally inherited forms of sudden cardiopulmonary arrest and HC. Mutations in mtDNA that lead to HC include A-to-G and C-to-T transitions at nucleotide 3260 and nucleotide 3303, respectively, in tRNALeU(UUR); A-to-G transitions at nucleotide 4317 and nucleotide 4266 in tRNAlle; and, possibly, an A-to-G transition at nucleotide 15951 in tRNAThr. A novel point mutation (T to C) was found in the mitochondrial tRNAgly gene at 
Table IV. Frequency of some polymorphisms among Iranian HCM patients

\begin{tabular}{|c|c|c|c|c|c|}
\hline Locus & $\begin{array}{l}\text { Nucleotide } \\
\text { position }\end{array}$ & $\begin{array}{l}\text { Frequency } \\
\text { (31 patients) }\end{array}$ & $\begin{array}{l}\text { Nucleotide } \\
\text { change }\end{array}$ & $\begin{array}{l}\text { Amino acid } \\
\text { change }\end{array}$ & $\begin{array}{l}\text { Reported in MitoMap } \\
\text { references }\end{array}$ \\
\hline \multirow[t]{19}{*}{ RNR2 } & 1700 & 1 & $\mathrm{~T}-\mathrm{C}$ & Non-coding & + \\
\hline & 1718 & 1 & $A-A A$ & Non-coding & + \\
\hline & 1719 & 1 & $\mathrm{G}-\mathrm{A}$ & Non-coding & ${ }^{*}+$ \\
\hline & 1810 & 1 & $A-G$ & Non-coding & Unpublished \\
\hline & 1811 & 2 & $A-G$ & Non-coding & + \\
\hline & 1888 & 2 & $G-A$ & Non-coding & + \\
\hline & 1977 & 1 & $\mathrm{~T}-\mathrm{C}$ & Non-coding & ${ }^{*}+$ \\
\hline & 2071 & 1 & $\mathrm{~T}-\mathrm{C}$ & Non-coding & Unpublished \\
\hline & 2260 & 1 & $A-C$ & Non-coding & Unpublished \\
\hline & 2306 & 1 & $A-T$ & Non-coding & Unpublished \\
\hline & 2706 & 15 & $A-G$ & Non-coding & * + \\
\hline & 2707 & 1 & $A-C$ & Non-coding & + \\
\hline & 2778 & 1 & $\mathrm{~T}-\mathrm{C}$ & Non-coding & Unpublished \\
\hline & 2805 & 1 & $A-T$ & Non-coding & Unpublished \\
\hline & 3010 & 3 & $G-A$ & Non-coding & ${ }^{*}+$ \\
\hline & 3107 & 26 & $\mathrm{~N}-\mathrm{T}$ & rCRcorrection & ${ }^{*}+$ \\
\hline & 3170 & 1 & C-A & Non-coding & Unpublished \\
\hline & 3197 & 2 & $\mathrm{~T}-\mathrm{C}$ & Non-coding & + \\
\hline & 3202 & 1 & $\mathrm{~T}-\mathrm{C}$ & Non-coding & + \\
\hline TL1 & 3285 & 2 & $\mathrm{~T}-\mathrm{C}$ & Non-coding & ${ }^{*}+$ \\
\hline \multirow[t]{3}{*}{ ND1 } & 3338 & 1 & $\mathrm{~T}-\mathrm{C}$ & $\mathrm{V}-\mathrm{A}$ & ${ }^{*}+$ \\
\hline & 3392 & 1 & $\mathrm{G}-\mathrm{C}$ & $G-A$ & + \\
\hline & 3480 & 2 & $A-G$ & Syn & + \\
\hline TQ & 4384 & 1 & $\mathrm{~T}-\mathrm{C}$ & ?????? & Unpublished \\
\hline \multirow[t]{10}{*}{ ND2 } & 4529 & 1 & $A-T$ & Syn & + \\
\hline & 4646 & 2 & $\mathrm{~T}-\mathrm{C}$ & Syn & + \\
\hline & 4655 & 1 & $G-A$ & Syn & + \\
\hline & 4823 & 1 & $\mathrm{~T}-\mathrm{C}$ & Syn & + \\
\hline & 4917 & 2 & $A-G$ & $N-D$ & + \\
\hline & 5021 & 1 & $\mathrm{~T}-\mathrm{C}$ & Syn & Unpublished \\
\hline & 5046 & 3 & $\mathrm{G}-\mathrm{A}$ & V-A & + \\
\hline & 5460 & 4 & $G-A$ & $A-T$ & + \\
\hline & 5480 & 1 & $A-G$ & Syn & + \\
\hline & 5495 & 1 & $\mathrm{~T}-\mathrm{C}$ & Syn & + \\
\hline $\mathrm{CO} 2$ & 8251 & 1 & $\mathrm{G}-\mathrm{A}$ & Syn & + \\
\hline \multirow[t]{9}{*}{ ATP6 } & 8614 & 3 & $\mathrm{~T}-\mathrm{C}$ & Syn & + \\
\hline & 8682 & 1 & $A-G$ & Syn & Unpublished \\
\hline & 8648 & 1 & $\mathrm{G}-\mathrm{A}$ & $\mathrm{R}-\mathrm{Q}$ & + \\
\hline & 8697 & 2 & $G-A$ & Syn & + \\
\hline & 8701 & 2 & $A-G$ & T-A & ${ }^{*}+$ \\
\hline & 8705 & 1 & $\mathrm{~T}-\mathrm{C}$ & $M-T$ & + \\
\hline & 8860 & 30 & $A-G$ & T-A & ${ }^{*}+$ \\
\hline & 8994 & 1 & $G-A$ & Syn & + \\
\hline & & & & $\mathrm{S}-\mathrm{N}$ & \\
\hline
\end{tabular}

Reported among HCM patients before. rCRcorrection: $h$ ttp://www.mitomap.org/mitoseq.html 
nucleotide 9997 in a maternally affected inherited HC [16]. Only T4384C mutation was found in tRNA glutamine that affects the T_C loop among our patients. As this mutation has not been reported before, more investigation is needed to specify it accurately.

Unreported base substitutions in mtDNA were found in this study. Whereas the "silent" ones, i.e., not affecting amino acid composition of the encoded polypeptide, are generally assumed to represent polymorphism, the role of the others is less obvious.

An A-to-G transition at nucleotides 8860, previously characterized, was present in a high proportion (30 of 31 patients) in our study with respect to the Cambridge Reference Sequence [17]. While this polymorphism was found among idiopathic cardiomyopathic patients, it was considered as a possible error in the Cambridge sequence but future studies showed that it is a rare polymorphism [18]. In fact none of our 60 controls showed this polymorphism. Some other studies have found this transition in a high proportion, such as all 79 patients with Alzheimer's disease [19], all 23 patients affected with bipolar affective disorder [20], and 13/14 patients with Leber's hereditary optic neuropathy [21]. These findings suggest that this polymorphism may a have close relation with these kinds of mitochondrial degenerative diseases.

\section{Acknowledgments}

This work was supported by a grant (with research project No. 227) from the National Institute for Genetic Engineering and Biotechnology, Ministry of Science, Research and Technology, Tehran, Iran. We would like to thank the patients and their families, whose collaboration and understanding allowed us to do this work.

\section{References}

1. Turner LF, Kaddoura S, Harrington D, Cooper JM, PooleWilsonand PA, Schapira AH. Mitochondrial DNA in idiopathic cardiomyopathy. Eur Heart J 1998; 19: 1725-9.

2. Montazeri M, Houshmand M, Mehdi Shafa Shariat Panahi, et al. Investigation of polymorphisms in non-coding region of human mitochondrial DNA in 31 Iranian Hypertrophic Cardiomyopathy (HCM) patients. Iran J Biotechnol 2005; 3: 157-62.

3. Houshmand M, Panahi MS, Nafisi S, Soltanzadeh A, Alkandari FM. Identification and sizing of GAA trinucleotide repeat expansion, investigation for D-loop variations and mitochondrial deletions in Iranian patients with Friedreich's ataxia. Mitochondrion 2006; 6: 82-8.

4. Ahari SE, Houshmand M, Panahi MS, Kasraie S, Moin M, Bahar MA. Investigation on mitochondrial tRNA(Leu/Lys), NDI and ATPase 6/8 in Iranian multiple sclerosis patients. Cell Mol Neurobiol 2007; 27: 695-700.

5. Available at: http://www.gen.emory.edu/mitomap/ mitoseq.Html.
6. Available at: http://www.mitomap.org/cgi-bin/tbl7gen.pl.

7. Marian AJ. Modifier genes for hypertrophic cardiomyopathy. Curr Opin Cardiol 2002; 17: 242-52.

8. Ozawa T, Tanaka M, Sugiyama S, et al. Multiple mitochondrial DNA deletionsexist in cardiomyocytes of patients with hypertrophic or dilated cardiomyopathy. Biochem Biophys Res Commun 1990; 170: 830-6.

9. Ozawa T, Tanaka M, Sugiyama S, et al. Patients with idiopathic cardiomyopathy belong to the same mitochondrial DNA gene family of Parkinson's disease and mitochondrial encephalomyopathy. Biochem Biophys Res Commun 1991; 177: 518-25.

10. Goto Y, Nonaka I, Horai S. A mutation in thetRNALeu(UUR) gene associated with the MELAS subgroup of mitochondrial encephalomyopathies. Nature 1990; 348: 651-3.

11. Boulet L, Karpati G, Shoubridge EA. Distribution and threshold expression of the TRNALYs mutation in skeletal muscle of patients with myoclonic epilepsy and raggedred fibers (MERRF). Am J Hum Genet 1992; 51: 1187-200.

12. Moraes CT, Ricci E, Bonilla E, DiMauro S, Schon EA. The mitochondrial tRNALeU(UUR) mutation in mitochondrial encephalomyopathy, lactic acidosis and strokelike episodes (MELAS): genetic, biochemical, and morphological correlations in skeletal muscle. Am J Hum Genet 1992; 50: 934-49.

13. Schon EA, Koga Y, Davidson M, Moraes CT, King MP. The mitochondrial tRNALeu(UUR) mutation in MELAS: a model for pathogenesis. Biochem Biophys Acta 1992; 1101: 206-9.

14. Silvestri G, Moraes CT, Shanske S, Oh SJ, DiMauro S. A new mIDNA mutation in the tRNALYS gene associated with myoclonic epilepsy and ragged-red fibers (MERRF). Am J Hum Genet 1992; 51: 1213-7.

15. Koo B, Becker LE, Chuang S, et al. Mitochondrial encephalomyopathy, lactic acidosis, stroke-like episodes (MELAS): clinical, radiological, pathological and genetic observations. Ann Neurol 1993; 34: 25-32.

16. Merante F, Tein I, Benson L, Robinson BH. Maternally inherited hypertrophic cardiomyopathy due to a novel T-to-C transition at nucleotide 9997 in the mitochondrial tRNAgYcne gene. Am J Hum Genet 1994; 55: 437-46.

17. Andrews RM, Kubacka I, Chinnery PF, Lightowlers RN, Turnbull DM, Howell N. Reanalysis and revision of the Cambridge reference sequence for human mitochondrial DNA. Nat Genet 1999; 23: 147.

18. Lee MS, Levin BC. MitoAnalyzer: a computer program and interactive web site to determine the effects of single nucleotide polymorphisms andmutations in human mitochondrial DNA. Mitochondrion 2002; 321-6.

19. Mostafaie N, Rossmanith W, Hombauer H, et al. Mitochondrial genotype and risk for Alzheimer's disease: cross-sectional data from the Vienna-Transdanube-Aging "VITA" study. J Neural Transm 2004; 111: 1155-65.

20. Kirk R, Furlong RA, Amos W, et al. Mitochondrial genetic analyses suggest selection against maternal lineages in bipolar affective disorder. Am J Hum Genet 1999; 65: 508-518.

21. Fauser S, Luberichs J, Besch D, Leo-Kottler B. Sequence analysis of the complete mitochondrial genome in patients with Leber's hereditary optic neuropathy lacking the three most common pathogenic DNA mutations. Biochem Biophys Res Commun 2002; 295: 342-7. 